\title{
Paper-based laminates produced with kraft lignin-rich phenol-formaldehyde resoles meet requirements for outdoor usage
}

\author{
Masoumeh Ghorbani ${ }^{1}$ - Arunjunai Raj Mahendran ${ }^{2} \cdot$ Hendrikus W. G. van Herwijnen $^{2} \cdot$ Falk Liebner $^{3}$. \\ Johannes Konnerth ${ }^{1}$
}

Received: 23 March 2017 / Published online: 7 November 2017

(c) The Author(s) 2017. This article is an open access publication

\begin{abstract}
Suitability of lignin-phenol-formaldehyde (LPF) resoles was investigated for manufacturing paper-based high-pressure laminates. As lignin source, pine kraft lignin and spruce sodium lignosulfonate were compared, substituting $40 \mathrm{wt} \%$ of phenol by lignin in each case. The synthesized resins were characterized for their viscosity development, solid content, $\mathrm{pH}$, free formaldehyde as well as free phenol content and B-time. Paper-based high-pressure laminates were manufactured using the two different resins. The laminates were exposed to different test climates and were compared for boiling water resistance, thickness swelling, bending properties and impact energy. The results indicate that pine kraft lignin performs superior to spruce sodium lignosulfonate for utilization in paper based laminates for outdoor usage due to a lower affinity of the pine kraft LPF laminates to water.
\end{abstract}

\section{Introduction}

Paper-based high-pressure laminates, also known as compact panels according to EN 438 (2005) are frequently used for furniture, construction applications and outdoor applications like decorative facade elements, in wet room applications and others. This product category is one of the important application areas for phenol-formaldehyde (PF) resins, and more particular resoles (Pilato 2010; Pizzi 2015). PF resins are used for impregnation of the core layer papers of the laminates due to their excellent properties, such as moisture, heat, and chemical resistance (Pilato 2010). On the other hand, lignin as a phenolic and abundant natural polymer has been known as suitable phenol substitute for phenolic

Johannes Konnerth

johannes.konnerth@boku.ac.at

1 Institute of Wood Technology and Renewable Materials, Department of Material Sciences and Process Engineering, University of Natural Resources and Life Sciences Vienna, Konrad-Lorenz-Strasse 24, 3430 Tulln an der Donau, Austria

2 Wood K plus, Competence Centre for Wood Composites and Wood Chemistry, Altenberger Strasse 69, 4040 Linz, Austria

3 Division of Chemistry of Renewable Resources, Department of Chemistry, University of Natural Resources and Life Sciences Vienna, Konrad-Lorenz-Strasse 24, 3430 Tulln an der Donau, Austria resin production (Henriksson 2009) due to its content of different phenolic moieties (hydroxyphenyl, H; guaiacyl, G; syringyl; S units) which can undergo electrophilic aromatic substitution with formaldehyde in a similar fashion to phenol (Pilato 2010), even though the variability in overall H/G/S content, ratio, aromatic substitution pattern, and hence, reactivity - all of them largely affected by lignin origin and lignin isolation history - is still a challenge in LPF research. The considerably lower price of lignin (Ghorbani et al. 2016) as well as the environmental benefit of replacing the fossilbased toxic phenol has persuaded the wood adhesive industries to fortify their efforts to substitute phenol by lignin on a commercial scale (Pizzi 2013). However, the generally lower reactivity of lignin towards formaldehyde caused by the higher steric demand of the macromolecules, poorer accessibility of free reactive ring positions towards formaldehyde, lower count of reactive aromatic sites available for methylolation, and the required higher curing temperatures, are some of the factors hitherto impeding production and application of lignin-phenol-formaldehyde (LPF) resins on an industrial scale (Siddiqui 2013).

Lignins originating from different plant species and pulping processes have different macromolecular features including average molecular weight, molecular weight distribution, count and ratio of $\mathrm{H}, \mathrm{G}$ and $\mathrm{S}$ units or amphiphilicity which render them attractive for a wide range of applications. However, this implies as well that each type of lignin requires 
an individual evaluation with regard to its applicability for a particular application (Ghorbani et al. 2016; William 2014). The use of lignin-phenol-formaldehyde resoles in the manufacture of plywood, particleboard or fibreboard has already been investigated. However, even though the use of lignin in manufacturing decorative high-pressure laminates has been investigated a few decades ago to some extent (Seidle et al. 1944; Sibalis and Rosario 1980; Seidel and Fuller 1984), only little research has been conducted since then (Mahendran et al. 2010; Taverna et al. 2015). Kraft lignin and sodium lignosulfonate are the by-products of two major pulping processes. Owing to the differences in pulping chemistry, the properties of both lignins vary to a large extent as most apparent from the good water solubility of lignosulfonates at all $\mathrm{pH}$ which contrasts the water insolubility of kraft lignins except at very high $\mathrm{pH}$. Lignosulfonates are generally expected to have higher molecular weight and contain a high amount of sulfur compared to kraft lignin (Laurichesse and Averous 2014; William 2014).

In this work, the performance of LPF resole resins substituting $40 \mathrm{wt} \%$ of phenol by two types of lignin was investigated for paper-based laminate manufacture. The selected lignins were obtained from two different pulping processes (kraft and sulphite) and two different sources (softwood species). It was assumed that pine kraft lignin and spruce sodium lignosulfonate would afford resins of different adhesive properties translating into different performance of the respective high-pressure laminates produced thereof.

\section{Materials and methods}

\subsection{Material}

Pine kraft lignin (Indulin $\mathrm{AT}^{\mathrm{TM}}$ ) was purchased from Mead Westvaco Corp (Richmond, VA, USA) and spruce sodium lignosulfonate from BIOTECH Lignosulfonate Handels $\mathrm{GmbH}$ (Valentin, Austria). Both lignins were received in powder form and used without further purification or modification. Isopropanol, aqueous formaldehyde ( $37 \mathrm{wt} \%$ ), distilled water, hydroxylamine hydrochloride, sodium hydroxide solution $(1 \mathrm{~mol} / \mathrm{L})$ and hydrochloric acid $(1 \mathrm{~mol} / \mathrm{L})$ were purchased from Carl Roth GmbH \& Co. KG (Karlsruhe, Germany). Absorbex ${ }^{\circledR}$ kraft paper (Kotkamills Oy, Finland) was provided by FunderMax GmbH (Wiener Neudorf, Austria). Liquid phenol (92.6 wt\%), aqueous formaldehyde (55 wt $\%$ ) and aqueous sodium hydroxide (50 wt $\%$ ) were provided by Metadynea Austria GmbH (Krems, Austria).

\subsection{Resin preparation}

Lignin-phenol-formaldehyde (LPF) resin was synthesised as described in more detail in previous work (van Herwijnen and Prock 2009; Ghorbani et al. 2016). The formaldehyde content is corresponding to the molar ratio of formaldehyde to phenol of 2.5 as well as lignin-formaldehyde relationship of $0.22 \mathrm{~mol}$ formaldehyde per $100 \mathrm{~g}$ lignin, which was determined through a reactivity test (Malutan et al. 2008).

For the reactivity test, $112.5 \mathrm{~g}$ of lignin was placed in three-neck round-bottom flask and dissolved in $291 \mathrm{~g}$ aqueous $\mathrm{NaOH}$ solution $3 \%$ (wt/wt) corresponding to a $\mathrm{NaOH} /$ lignin ratio of $0.08(\mathrm{wt} / \mathrm{wt})$ at $25^{\circ} \mathrm{C}$. The flask was equipped with a condenser, electronic temperature controller, and magnetic stirring bar. $78.45 \mathrm{~g}$ formaldehyde solution (37\%) corresponding to a formaldehyde/lignin ratio of 0.26 (wt/ wt) was added at room temperature. The mixture was then heated up to $55^{\circ} \mathrm{C}$ to start methylolation. Free formaldehyde content was measured according to ISO 11402 (2004) every 50 min until a constant value was obtained. The fact that the formaldehyde concentration becomes constant and does not continuously decline is an indication that the Cannizzaro reaction (the base catalysed oxidation/reduction of formaldehyde yielding formic acid and methanol) does not occur to a significant extent. The total reaction time was $5 \mathrm{~h}$. At that point the ratio of lignin to consumed formaldehyde was $0.07 \mathrm{wt} / \mathrm{wt}$ (0.22 mol HCHO per $100 \mathrm{~g}$ lignin).

To prepare $4200 \mathrm{~g}$ liquid resin, $1040 \mathrm{~g}$ liquid phenol (92.6 wt \%) and $414 \mathrm{~g}$ aqueous sodium hydroxide (50 wt\%) were placed in a 5 -L three-neck flask equipped with a cooler coil, electronic temperature controller, a laboratory dosing pump and agitator. The mixture was heated to $65^{\circ} \mathrm{C}$, and $642 \mathrm{~g}$ lignin was added portion-wise over a period of $25 \mathrm{~min}$. Then $1467 \mathrm{~g}$ aqueous formaldehyde (55 wt\%) was added using the laboratory dosing pump. Through formaldehyde addition which lasted $30 \mathrm{~min}$, the temperature of the reaction mixture increased to $70{ }^{\circ} \mathrm{C}$. Cooking time as indicated in Table 1 was recorded after the completion of formaldehyde addition, and viscosity measurement was started after $20 \mathrm{~min}$ while conducted every $10 \mathrm{~min}$. Cooking was stopped when a viscosity of $150 \mathrm{mPa} \mathrm{s}$, a value suitable for paper impregnation, was reached by cooling down the resin immediately using a cooler coil.

\subsection{Resin characterisation}

Viscosity was measured according to DIN 16916-2 (1987) using cooled $\left(20^{\circ} \mathrm{C}\right)$ aliquots $(1 \mathrm{~mL})$ of the LPF pre-condensates. A cone-plate rheometer (Bohlin CVO; Malvern Instruments Limited, Malvern, UK) equipped with a temperature control unit was used with a rotation speed of $200 / \mathrm{cm}$.

Free formaldehyde content was determined according to ISO 11402 (2004) by reaction of a defined amount of sample with excess hydroxylamine hydrochloride and titration of the released $\mathrm{HCl}$ using $1 \mathrm{M} \mathrm{NaOH}$. A defined amount of resin $(5.0 \pm 0.2 \mathrm{~g})$ was dissolved in $50 \mathrm{~mL}$ of an isopropanol-water mixture $(3: 1 \mathrm{v} / \mathrm{v})$. The solution was titrated with 
Table 1 Properties of LPF resin substituting $40 \mathrm{wt} \%$ of phenol by pine kraft lignin (PKL-PF) and sodium lignosulfonate (SSOL-PF)

\begin{tabular}{llllllll}
\hline Resin type & $\begin{array}{l}\text { Cooking } \\
\text { time (min) }\end{array}$ & $\begin{array}{l}\text { Viscosity } \\
\text { (mPa s) }\end{array}$ & Final pH & $\begin{array}{l}\text { Solid } \\
\text { content } \\
(\mathrm{wt} \%)\end{array}$ & $\begin{array}{l}\text { Free formal- } \\
\text { dehyde }(\mathrm{wt} \%)\end{array}$ & $\begin{array}{l}\text { Free } \\
\text { phenol } \\
(\mathrm{wt} \%)\end{array}$ & B-time at $130{ }^{\circ} \mathrm{C}$ \\
\hline PKL-PF & 20 & 162 & 9.9 & $51.7 \%$ & $1.7 \%$ & 1.06 & 2 min $47 \mathrm{~s}$ \\
SSOL-PF & 95 & 151 & 10.0 & $51.7 \%$ & $1.1 \%$ & 0.31 & 2 min $25 \mathrm{~s}$ \\
\hline
\end{tabular}

hydrochloric acid $(0.1 \mathrm{~mol} / \mathrm{L})$ using a TitroLine ${ }^{\circledR} 6000 / 7000$ titrator (SI Analytics, Mainz, Germany) to adjust the $\mathrm{pH}$ to 3.5. Then $25 \mathrm{~mL}$ of hydroxylamine hydrochloride solution (10 wt \%) was added to the solution and stirred for $10 \mathrm{~min}$. The solution was immediately titrated with sodium hydroxide solution $(1 \mathrm{~mol} / \mathrm{L})$ to a $\mathrm{pH}$ of 3.5 . The free formaldehyde content as a percentage by mass was then calculated using a standard equation (ISO 11402 2004).

Free phenol in the resins was determined by Methadynea Austria (Krems, Austria) on a ICS 5000 HPLC system (Thermo Scientific, Waltham, MA, USA) equipped with Chromolith RP-18e $100 \times 4.6 \mathrm{~mm}$ column and a UV-detector $(271 \mathrm{~nm})$ using phenol as an external standard.

Solid content was determined according to ISO 3251 (2008). All samples were initially cured and equilibrated in a ventilated oven at $135{ }^{\circ} \mathrm{C}$ for $24 \mathrm{~h}$.

The time required to reach the B-stage of resin (B-time) was measured according to DIN 16916 (1987) using selfconstructed equipment. The latter consists of a heated aluminium plate with a depression (diameter $25 \mathrm{~mm}$, depth $5 \mathrm{~mm}$ ) on it and a Pt100 temperature sensor for precise temperature control (accuracy $\pm 0.5^{\circ} \mathrm{C}$ ). A precise amount of $500 \mathrm{mg}$ was placed into the depression at a plate temperature of $130{ }^{\circ} \mathrm{C}$. A glass rod was used to stir the sample for $1 \mathrm{~min}$. After that, samples were stirred every minute for $10 \mathrm{~s}$ until the B-stage was reached. This was the case when the resin sample was no longer stringy and could be torn off at the end of the glass rod while it was pulled out.

\subsection{Preparation of compact panels}

Absorbex ${ }^{\circledR}$ kraft paper was impregnated with the prepared resins which had been diluted before with a volume of methanol corresponding to $20 \%$ of the resin volume using a self-constructed laboratory impregnation device (FunderMax GmbH, Wiener Neudorf, Austria). Briefly, paper from an unwinding device was transferred to the LPF resole bath. The resin content of the paper was adjusted by the gap size of squeezer rolls in combination with the feed speed of the paper until a resin load of $50 \mathrm{wt} \%$ dry resin related to the mass of dry paper was reached. Then the wet paper moved to the tunnel drying section which was ventilated with hot air $\left(150{ }^{\circ} \mathrm{C}\right)$ for approximately $45 \mathrm{~s}$. Sheets of $30 \times 30 \mathrm{~cm}$ were cut out of the impregnated paper roll. For each resin type two panels and for each panel 15 pieces of paper were used as a core while they were covered with an industrial melamine-impregnated decorative paper layer provided by FunderMax GmbH (Wiener Neudorf, Austria). The prepared panels were hot pressed at $145^{\circ} \mathrm{C}$ and $6 \mathrm{MPa}$ for $11.5 \mathrm{~min}$ using a WKP 2000 multi-daylight press (Wickert-Presstech, Germany). The final thickness of pressed panels was about $4 \mathrm{~mm}$.

\subsection{Characterization of compact panels}

Density distribution within the panels was calculated by the formula $\rho=\mathrm{m} / \mathrm{V}$, where $\rho$ is apparent density, $m$ the mass and $\mathrm{V}$ the volume of the sample. Samples were taken from all different cutting directions according to EN 438-2 (2005), ISO 178 (2003) and ISO 179 (2001).

Resistance to boiling water was determined considering thickness and mass increase according to EN 438-2 (2005). The thickness and weight of the panel samples were measured in standard climatic condition $\left(20^{\circ} \mathrm{C}, 65 \%\right.$ relative humidity) before and after the treatment.

Bending strength and modulus of elasticity were determined according to ISO 178 (2003) using a Zwick/Roell Z100 universal testing machine (Zwick GmbH \& Co. KG, Ulm, Germany) using a cross head speed of $2 \mathrm{~mm} / \mathrm{min}$. The test was performed for the panel samples conditioned in standard climate (non-treated samples) and panels subjected to harsh weathering conditions according to EN 438-2 (2005) (sequence of fast changing warm-dry, warmhumid and cold-dry climate conditions for 20 days).

Impact energy was measured according to ISO 179 (2001) using a Zwick/Roell HIT 50 device (Zwick GmbH \& Co. KG, Ulm, Germany) equipped with an instrumented impact pendulum with nominal impact energy of $5 \mathrm{~J}$. Relative impact energy was calculated by relating the energy to the individual density of the sample.

\section{Results and discussion}

The results of this study generally confirm that lignins obtained by two of the most important wood pulping technologies can be used to prepare PF resole adhesives for paper-based laminates in which $40 \mathrm{wt} \%$ of phenol is replaced by the respective lignin. However, major differences have 
been identified comprising synthesis behaviour, LPF product properties and performance of the final paper based laminates. Some selected properties of the LPF resins substituting $40 \mathrm{wt} \%$ of phenol by pine kraft lignin and sodium lignosulfonate are summarized in Table 1. A significantly longer cooking time was observed for the resin that contained lignosulfonate (SSOL-PF) which could be due to the different molecular structure of the lignins incorporated. Polymerization rate and consequently cooking time are influenced by molecular weight of lignin incorporated into the LPF resin (Ghorbani et al. 2016). However, molecular weight does not seem to be the only factor influencing LPF network expansion (Ghorbani et al. 2017a). Although lignosulfonates generally tend to have higher molecular weight than kraft lignin (Laurichesse and Averous 2014), which could explain faster viscosity development (Ghorbani et al. 2016), alkaline sodium sulphite pulping results also in low molecular lignin fragments. In previous studies, molecular weight of identical pine kraft lignin and sodium lignosulfonate feedstock was reported to be 3971 and $3343 \mathrm{~g} / \mathrm{mol}$, respectively (Ghorbani et al. 2017a, b). As these small differences could not fully explain the significantly deferred mechanism of crosslinking, an assumed higher linearity of the structure of sodium lignosulfonate (William 2014) or lower content of phenolic $\mathrm{OH}$ groups seem to be possible causes for the observed longer cooking time needed for SSOL-PF resin. Using ${ }^{31} \mathrm{P}-\mathrm{NMR}$ spectroscopy, phenolic $\mathrm{OH}$ groups for pine kraft lignin and sodium lignosulfonate were reported to be in the range of 2.90 and $1.17 \mathrm{mmol} / \mathrm{g}$, respectively (Ghorbani et al. 2017a, b). In spite of the lower phenolic OH content of sodium lignosulfonate, the SSOL-PF resin seems to be condensed to a higher extent, resulting in a slightly lower content of free monomers (phenol and formaldehyde) and shorter curing time (B-time) which could be due to the less steric hindrance caused by its slightly lower molecular weight. The other properties, i.e. $\mathrm{pH}$ and solid content, were in a comparable range (Table 1).

The density of paper-based laminates is an important criterion for usage as density directly influences mechanical properties. Among the laminate types tested only those prepared under addition of kraft lignin met the standard requirement $\left[\rho \geq 1.35 \mathrm{~g} / \mathrm{cm}^{3}\right.$ (EN 438-1 2005)], while the density of SSOL-PF bonded panels was somewhat too low (cf. Fig. 1a). As 4 mm nominal thickness was used for panel preparation, small thickness variations in the range of some hundredth of mm explain the observed differences and variation in density. These variations do not seem to have a direct relation to resin properties. The specific density variation of the ready-to-use paper-based laminates is shown in Fig. 1A.

Water absorption and swelling are properties not desired for paper-based laminates in outdoor applications as water uptake accelerates physical and chemical weathering, favors microbial degradation and leads to internal stresses and crack formation. The data shown in Fig. 1 reveal that panels prepared with SSOL-PF resin absorb significantly more water than PKL-PF based panels. This water uptake goes obviously along with higher thickness swelling. Both standard values in terms of water absorption and thickness swelling could not be passed by the SSOL-PF based panel. This observation could be attributed to the unparalleled higher polarity and, hence, hydrophilicity of the lignosulfonates caused by the abundance of sulfonate groups which are not inherent to kraft lignin (Thakur et al. 2014; Yan and Yang 2015). Owing to the high alkalinity $(\mathrm{pH}>>7)$ and particular curing chemistry of phenol-formaldehyde resins, the abundance of sulfonate groups is assumed to be largely preserved in cured SSOL-PF resins which imparts them higher hydrophilicity as determined for PKL-PF resins.
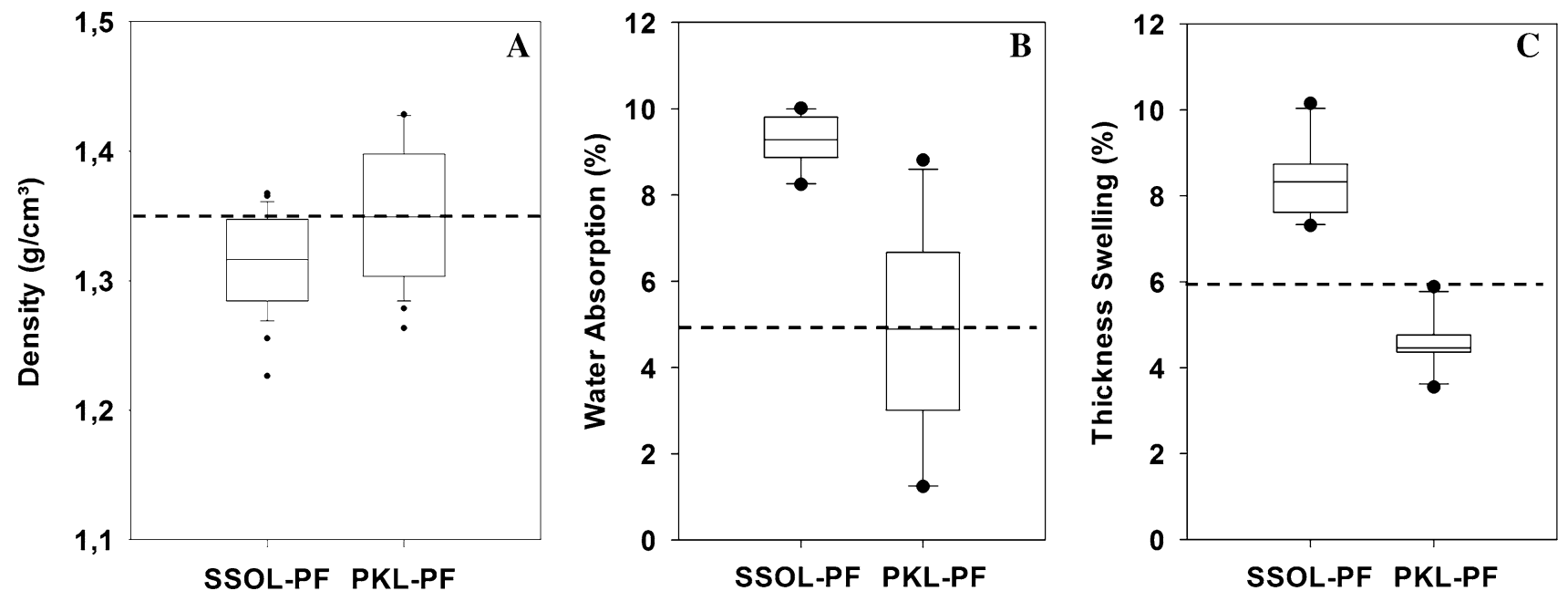

Fig. 1 Density $(\mathbf{a} n=28)$, water absorption $(\mathbf{b} n=8)$ and thickness swelling $(\mathbf{c} n=8)$ of the panels prepared with the LPF resins substituting $40 \mathrm{wt} \%$ of phenol by sodium lignosulfonate (SSOL-PF) and pine kraft lignin (PKL-PF). Dashed lines represent standard requirements 
Bending strength $(\sigma)$ and modulus of elasticity $(E)$ are two major mechanical material parameters important to many applications, as it is the case for paper based laminates and their use in flooring, furniture or as decorative facade panels. While flexural strength represents the highest stress experienced within the material at its moment of failure, modulus of elasticity reports the resistance of a material towards elastic, non-permanent deformation. A comparison of both $E$ and $\sigma$ values of the laminates prepared in this study with the respective standard requirements for outdoor usage (EN 438-2 2005) confirmed that all samples conditioned in standard climate $\left(20{ }^{\circ} \mathrm{C}, 65 \%\right.$ relative humidity) can easily pass the test (Figs. 2, 3). Exposure of the samples to harsh weathering conditions, however, in terms of rapidly changing warm-dry, warm-humid and cold-dry climate conditions over a time period of 20 days (EN 438-2 2005) revealed significant differences between the two sets of samples with regard to $E$ and $\sigma$. While the laminates prepared from the kraft lignin containing PKL-PF resin were virtually not affected by the harsh treatment and fully complied with the requirements, E values of the laminates prepared from lignosulfonate containing SSOL-PF resins were below the threshold of $9 \mathrm{GPa}$. Similarly, flexural strength was also lower for SSOL-PF resins, however, still well meeting the requirements. It is obvious that the observed differences in flexural strength and stiffness are caused by the different hydrophilicity of the resins which is much higher when lignosulfonates are used instead of kraft lignin to replace $40 \mathrm{wt} \%$ of phenol as accomplished in this study.

Impact tests can provide valuable information on the failure behavior of materials or components subjected to rapid loading and varying climatic conditions. Therefore, the two

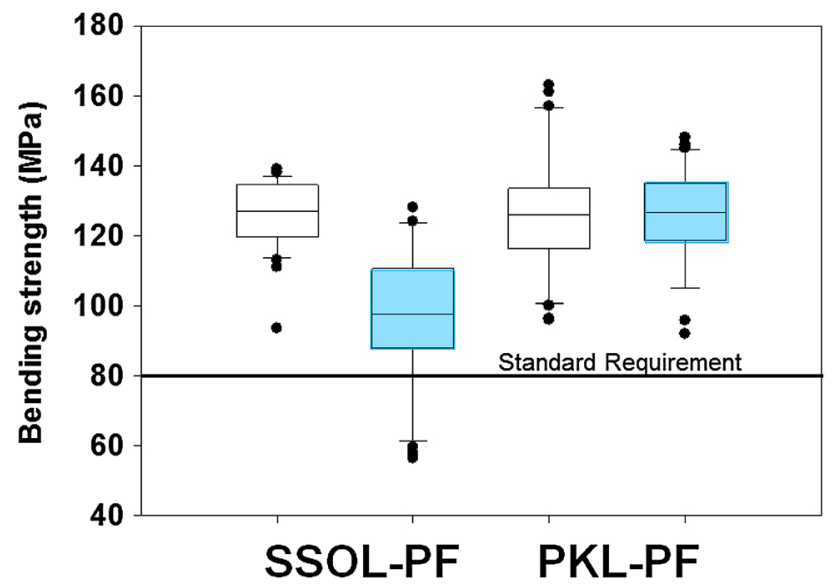

Fig. 2 Box plot of bending strength values of panels prepared with LPF resins substituting $40 \mathrm{wt} \%$ of phenol by sodium lignosulfonate (SSOL-PF) and pine kraft lignin (PKL-PF). The boxes represent the bending strength values (median, upper and lower quartiles, whiskers, and outliers; $n=28$ each) after exposure of the laminates to standard (empty) and harsh (filled) climatic conditions, respectively

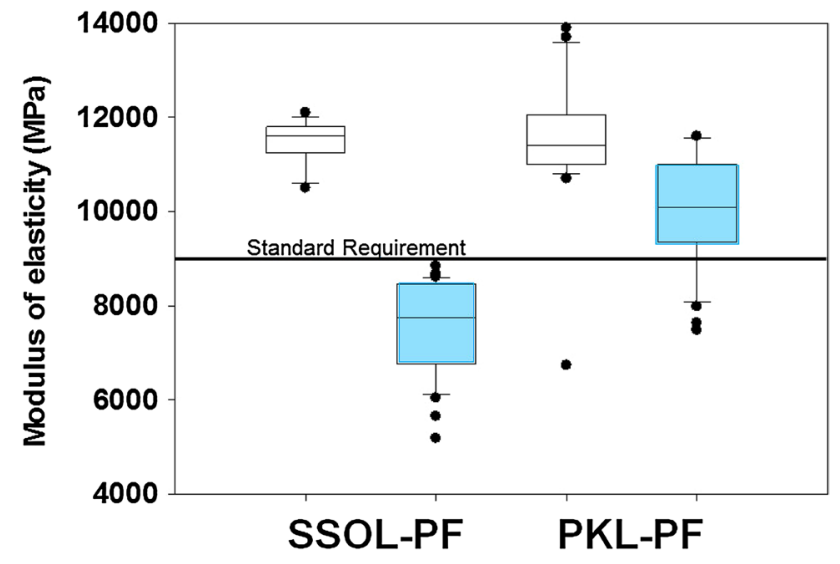

Fig. 3 Box plot of the moduls of elasticity for panels prepared with LPF resins substituting $40 \mathrm{wt} \%$ of phenol by sodium lignosulfonate (SSOL-PF) and pine kraft lignin (PKL-PF). The boxes represent values for modulus of elasticity (median, upper and lower quartiles, whiskers, and outliers; $n=28$ each) after exposure of the laminates to standard (empty) and harsh (filled) climatic conditions, respectively

sets of laminates each conditioned at mild and harsh climatic conditions were subjected to respective tests. Owing to the comparatively strong scattering of the bulk density of the prepared laminates, the observed impact energy values were normalized for the density of each sample yielding relative impact energy values $E^{*}$ (Fig. 4). The results reveal that independent of the type of resin used, all panels equilibrated at standard climatic conditions performed very similar. Exposure to rapid climate change increased the relative impact energy for both types of panels, which might be caused by softening (reduction of elastic modulus combined with a higher deformability) which was also observed when quasi static testing was applied. Here the panels prepared

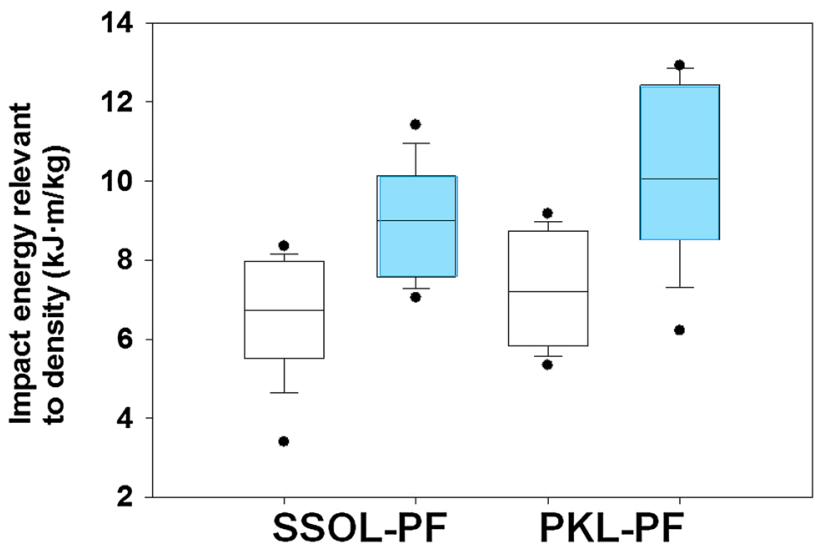

Fig. 4 Impact energy related to density $E^{*}$ of panels prepared with LPF resins substituting $40 \mathrm{wt} \%$ of phenol by sodium lignosulfonate (SSOL-PF) and pine kraft lignin (PKL-PF). The boxes represent the $\mathrm{E}^{*}$ values (median, upper and lower quartiles, whiskers, and outliers; $\mathrm{n}=10$ each) after exposure of the laminates to standard (empty) and harsh (filled) climatic conditions, respectively 
with PKL-PF showed a slightly higher increase in impact energy compared to the SOL-PF based panel. Anyhow, the differences observed between two resins types are not significant.

The mechanical performance of the laminates prepared in this study are in good agreement with a study by Taverna et al. (2015) who explored the use of LPF resins substituting $10 \mathrm{wt} \%$ phenol by kraft lignin and sodium lignosulfonate, respectively, to manufacture paper based laminates.

\section{Conclusion}

Paper-based laminates were successfully prepared using LPF resins substituting $40 \mathrm{wt}$. $\%$ of phenol by pine kraft lignin and sodium lignosulfonate, respectively. The laminates prepared with pine kraft lignin could basically fulfil the standard requirements for outdoor usage as governed by EN 438-2 (2005) and demonstrated for water absorption, thickness swelling and mechanical properties like flexural strength, elastic modulus and relative impact energy. In contrast, laminates prepared with spruce sodium lignosulfonate instead of pine kraft lignin failed in some of the tests due to their higher hydrophilicity, especially when the panels were subjected to rapid and frequent changes in temperature and humidity.

\begin{abstract}
Acknowledgements Open access funding provided by University of Natural Resources and Life Sciences Vienna (BOKU). The authors would like to acknowledge the financial support provided by FFG through the COMET-project FLIPPR "Future Lignin and Pulp Processing Research". Paper-based laminates were manufactured and mechanical testing was performed by students of the Master program "Wood Technology and Management" of BOKU University of Natural Resources and Life Sciences, Vienna during the laboratory course "Wood industry laboratory". The contribution of the following students is acknowledged: Clemens Huber, Michael Krumay, Michael Laffer, David Obernosterer, Max Pramreiter, and Alexander Stadlmann. Sincere thanks to the companies Metadynea Austria GmbH (Krems, Austria), in particular Dr. Wolfgang Kantner and FunderMax GmbH (Wiener Neudorf, Austria), in particular Mr. Patrick Domnanich for their great cooperation in providing free access to laboratory equipment: reactors for synthesis of the resins, determination of free phenol content; paper impregnation and laminate production.
\end{abstract}

Open Access This article is distributed under the terms of the Creative Commons Attribution 4.0 International License (http://creativecommons.org/licenses/by/4.0/), which permits unrestricted use, distribution, and reproduction in any medium, provided you give appropriate credit to the original author(s) and the source, provide a link to the Creative Commons license, and indicate if changes were made.

\section{References}

DIN-16916-2 (1987) Plastics; phenolic resins; testing. German Institute for Standardization, Berlin
EN-438-1 (2005) High-pressure decorative laminates (HPL)-sheets based on thermosetting resins (usually called laminates) - part 1: introduction and general information. Austrian Standard Institute, Vienna

EN-438-2 (2005) High-pressure decorative laminates (HPL)-Sheets based on thermosetting resins (Usually called Laminates) — part 2: determination of properties. Austrian Standard Institute, Vienna

Ghorbani M, Liebner F, van Herwijnen HWG, Pfungen L, Krahofer M, Budjav E, Konnerth J (2016) Lignin phenol formaldehyde resoles: the impact of lignin type on adhesive properties. Bioresources 11(3):6727-6741

Ghorbani M, Konnerth J, Budjav E, Requejo Silva A, van Herwijnen HWG, Zinovyev G, Edler M, Griesser T, Liebner F (2017a) Ammoxidized fenton-activated pine kraft lignin accelerates synthesis and curing of resole resins. Polymers 9(2):43

Ghorbani M, Konnerth J, van Herwijnen HWG, Budjav E, Requejo Silva A, Liebner F (2017b) Commercial lignosulfonates from different sulfite processes as partial phenol replacement in PF resole resins. J Appl Polym Sci. doi:10.1002/app.45893

Henriksson G (2009) Wood chemistry and biotechnology. De Gruyter, Stockholm

ISO-11402 (2004) Phenolic, amino and condensation resins determination of free formaldehyd. International Organization for Standardization, Geneva

ISO-178 (2003) Plastics-determination of flexural properties. Austrian Standard Institute, Vienna

ISO-179 (2001) Plastics-determination of Charpy impact properties. German Institute for Standardization, Berlin

ISO-3251 (2008) Paints, vanishes and plastics-determination of non-volatile-matter content. International Organization for Standardization, Geneva

Laurichesse S, Averous L (2014) Chemical modification of lignins: towards biobased polymers. Prog Polym Sci 39:1266-1290

Mahendran A, Wuzella G, Kandelbauer A (2010) Thermal characterization of kraft lignin phenol-formaldehyde resin for paper impregnation. J Adhes Sci Technol 24(8-10):1553-1565

Malutan T, Nicu R, Popa V (2008) Contribution to the study of hydroxymetylation reaction of alkali lignin. BioResources 3(1):13-20

Pilato L (2010) Phenolic resins: a century of progress. Springer, Berlin

Pizzi A (2013) Bioadhesives for wood and fibres: a critical review. Rev Adhes Adhes 1(1):88-113

Pizzi A (2015) Wood products and green chemistry. Ann For Sci 73(1):185-203

Seidel MP, Fuller TJ (1984) Sulfur containing lignin modified alkaline earth treated phenolic impregnated resin. US Patent 4476193 A

Seidle RJ, Burr HK, Ferguson CN, Mackin GE (1944) Properties of laminated plastics made from lignin and lignin-phenolic resin impragnated papers. Department of Agriculture, Forest Service, Forest Products Laboratory, Madison

Sibalis J, Rosario R (1980) Laminates containing lignosulfonateextended phenolic resins and process for manufacturing same. Eur Pat 0020004:A1

Siddiqui H (2013) Production of lignin-based phenolic resins using de-polymerized kraft lignin and process. Master thesis. University of Western Ontario, Ontario, Canada

Taverna ME, Ollearo R, Morán J, Nicolau V, Estenoz D, Frontini P (2015) Mechanical evaluation of laminates based on phenolic resins using lignins as partial substitutes for phenol. Bioresources 10(4):8325-8338 
Thakur V, Thakur M, Raghavan P, Kessler M (2014) Progress in green polymer composites from lignin for multifunctional applications: a review. ACS Sustain Chem Eng 2:1072-1092

van Herwijnen HWG, Prock C (2009) A water dilutable resin composition. Patent WO2009040415 (A1). Dynea Oy
William JP (2014) Sulfonation of kraft lignin to water soluble value added products. Master thesis. Lakehead University, Ontario, Canada

Yan M, Yang D (2015) Adsorption mechanism of lignosulfonate at the air/liquid interface. J Braz Chem Soc 26(3):555-561 